\title{
Mechanical Behaviour of Metallic Yielding Dampers with Different Aspect Ratios
}

\author{
Ahmed Sabah Aljawadia (D), Sophia C. Alih ${ }^{\text {b* }}$ (D), Mohammadreza Vafaei ${ }^{a}$ (D) \\ ${ }^{a}$ Faculty of Engineering, School of Civil Engineering, Universiti Teknologi Malaysia, Skudai, Malaysia. E-mail: aljawadi.as@gmail.com, \\ vafaei@utm.my \\ ${ }^{\mathrm{b}}$ Institute of Noise and Vibration, School of Civil Engineering, Universiti Teknologi Malaysia, Skudai, Malaysia.E-mail: sophiacalih@utm.my \\ * Corresponding author
}

https://doi.org/10.1590/1679-78256350

\begin{abstract}
Yielding shear plates have been widely used in metallic dampers as the primary source of energy dissipation. This study investigated the behavior of yielding shear plates with different aspect ratios when subjected to a gradually increasing lateral load. Five shear links with the thickness of $1 \mathrm{~mm}$ and aspect ratios ranging from 1.0 to 1.5 were constructed and tested. The force-displacement relationships of the shear links were idealized and represented by bilinear curves. The obtained results indicated that the square shear links had a larger displacement ductility ratio, initial and effective stiffness when compared with rectangular shear links. It was also observed that the initial, effective, and post-yield stiffness of square shear links were increased as their size was increased. However, the displacement ductility ratio of shear links with square diaphragm was decreased as the size of the shear link was increased.
\end{abstract}

\section{Keywords}

Metallic damper, shear plate, shear yield strength, plate aspect ratio, square plate, rectangular plate

\section{Graphical Abstract}
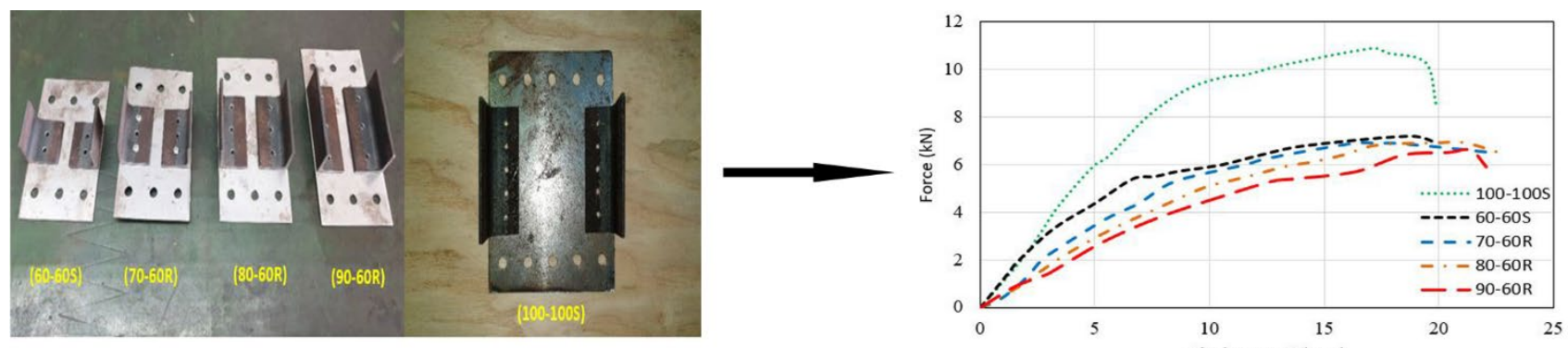

\begin{tabular}{|c|c|c|c|c|c|c|c|c|}
\hline \multirow[t]{2}{*}{ Specimen } & \multirow{2}{*}{$\begin{array}{c}\text { Initial } \\
\text { stiffness } \\
(\mathrm{kN} / \mathrm{mm})\end{array}$} & \multirow{2}{*}{$\begin{array}{l}\text { Effective } \\
\text { stiffness } \\
(\mathrm{kN} / \mathrm{mm})\end{array}$} & \multirow{2}{*}{$\begin{array}{l}\text { Post-yield } \\
\text { stiffness } \\
(\mathrm{kN} / \mathrm{mm})\end{array}$} & \multicolumn{2}{|c|}{$\begin{array}{l}\text { Displacement } \\
(\mathrm{mm})\end{array}$} & \multicolumn{2}{|c|}{ Strength $(\mathrm{kN})$} & \multirow[t]{2}{*}{$\begin{array}{l}\text { Dis. ductility ratio } \\
\qquad(\delta u / \delta y)\end{array}$} \\
\hline & & & & $\delta u$ & $\delta y$ & $\mathrm{Fu}$ & $\mathrm{Fy}$ & \\
\hline $60-60 S$ & 1.2 & 1.05 & 0.14 & 18.88 & 4.96 & 7.2 & 5.2 & 3.81 \\
\hline $70-60 R$ & 0.75 & 0.71 & 0.14 & 15.82 & 8.19 & 6.9 & 5.8 & 1.93 \\
\hline $80-60 R$ & 0.6 & 0.53 & 0.09 & 21.17 & 11.27 & 6.9 & 6 & 1.88 \\
\hline $90-60 R$ & 0.5 & 0.46 & 0.11 & 21.66 & 11.86 & 6.6 & 5.5 & 1.83 \\
\hline $100-100 \mathrm{~s}$ & 1.30 & 1.14 & 0.22 & 17.06 & 7.79 & 10.9 & 8.9 & 2.19 \\
\hline
\end{tabular}




\section{INTRODUCTION}

Metallic dampers have been widely employed in structures for protecting them against seismic actions. A metallic damper dissipates the input energy through inelastic deformation in steel plates and benefits from stable hysteresis loops, rate independency, resistance to ambient temperature, and ease of installation (Karavasilis et al., 2014). Although friction dampers also have stable hysteresis loops with good energy dissipation, the friction dampers' estimated friction response should be maintained over their life cycle. The cyclic response of a friction damper mostly relies on the surface condition of two solid bodies, which can be affected by environmental factors (Edrees, 2015). So far, different types of metallic dampers have been invented and put into practice by researchers. Some well-known examples of such metallic dampers include the hourglass shape dampers (i.e., ADAS) (Bergman and Goel, 1987), triangular shape dampers (i.e., TADAS) (Tsai et al., 1993), buckling-restrained brace (i.e., BRB) (Black et al., 2004) and slit steel dampers (i.e., SSD) (Chan and Albermani, 2008; Lee et al., 2015; Vafaei et al., 2019). The cyclic behavior of shear-and-flexural yielding metallic dampers have also been investigated, and it has been shown that for the same level of lateral strength and energy dissipation, they require less material (Sahoo et al., 2015).

Many metallic dampers use the flexural yielding of steel plates for energy dissipation. However, Nakashima et al. (1994) suggested the use of a shear panel damper (SPD) to dissipate the input energy through the inelastic shear deformation. The SPD consists of a steel plate welded to the top and bottom plates. It dissipates the input energy through the inelastic shear deformation (i.e., yielding/buckling) of metallic (steel or aluminum) plates under in-plane loading. Shear yielding of steel (web) plates through cyclic loading condition establish a consistent and substantial energy dissipation capacity. Chen et al. (2006) enhanced the cyclic behavior of the SPD by adding extra stiffeners to the shear links. The stiffened shear panel damper (SSPD) was constructed from a shear panel using horizontal and vertical stiffeners. The stiffness of SSPD was comparatively higher than that of the SPD, and it showed a larger deformation capacity without any sign of pinching or strength deterioration.

Zhang et al. (2012) also improved the cyclic response of the SPD through the use of low yield strength steel plates. In order to increase the energy dissipation capacity of the SPD dampers, shape optimization has been taken into account by some researchers (Deng et al., 2014). Chan et al. (2009) introduced a yielding shear panel device (YSPD), which was consisted of a steel plate welded inside a short hollow square (SHS). The SHS offers a boundary to the installed diaphragm plate so that a thin plate can also experience a shear deformation without buckling. It also provides an appropriate link with the parent structural frame, and assists in anchoring the tension field at the time of the post-buckling of the diaphragm plate (Nath, 2016). The YSPD uses the shear yielding established in the post-buckling for dissipating the energy of an earthquake.

Chan et al. (2013) worked on a perforated yielding shear panel device (PYSPD). The PYSPD uses a thin steel plate with numerous circular holes. Through piercing the steel plate, the issue of local deformation that was seen in YSPDs could be avoided. Sahoo et al. (2015) employed an X-shaped plate together with an SPD in order to produce an innovative energy dissipating device that was called the shear-and-flexural yielding damper (SAFYD). This damper was made by a shear steel plate in the middle, and an X-shaped steel plate on either end. For energy dissipation, the damper takes advantage of the flexural deformation of the X-plates together with the shear deformation of the web plate. Such configuration also allows for a superior level of lateral strength and stiffness compared with SPD. In another study, Deng et al. (2015) introduced the buckling restrained shear panel damper (BRSPD). The damper consisted of a steel shear panel, which was held back by two steel plates. These two plates enveloped the shear panels in order to decrease their out-of-plane buckling. In another study, a shear damper called the welded wide flange fuse (WWFF) was suggested by Yang et al. (2018). An in-depth experimental study denoted that the WWFF had consistent energy dissipation ability, thus making it an appropriately reliable metallic damper.

A review of the literature shows that, so far, many metallic dampers have been invented and tested by researchers. The optimal design of metallic dampers have mainly included the location and size of stiffeners (Ohsaki and Nakajima, 2012), shear panels with reduced thickness at the center (Zhang et al., 2012), arc-shaped shear plates (Liu et al., 2013), or shear plates with parabola-shaped side edges (Deng et al., 2014; Liu and Shimoda, 2013) .However, there is a limited study that investigates the effects of the shear plate's aspect ratio on their mechanical behavior. Therefore, in this study, experimental works were carried out to investigate to what extent the aspect ratio of a shear plate influences its mechanical behavior. Besides, the outcome of this study can help to select an optimal aspect ratio for steel plates when they are used in a metallic damper for energy dissipation through inelastic shear deformation. This study's outcome can help design engineers better understand the effects of steel shear plates' aspect ratio on the stiffness, strength, and energy dissipation capacity of metallic dampers

\section{TEST PROGRAM}

\subsection{Details of test specimens}

In this study, totally five shear plates were constructed and tested. As can be seen from Figures 1 and 2 , the test specimens were connected to two steel angles from sides and two steel plates from top and bottom. The steel angles were used to increase the out-of-plane stiffness of the shear plate and avoid the out-of-plane buckling. The shear plates were sandwiched between two support plates located at their top and bottom. The top support plates were welded to 
a steel plate, which was used for the loading of test specimens. The bottom support plates were welded to another steel plate, which was used to fix the shear plates to a rigid steel beam (see Figure 3). The connection between the shear plates and steel angles was through bolts. Moreover, three $6 \mathrm{~mm}$ diameter bolts connected the shear plates to the support plates. The size of these bolts was determined such that they remained elastic under the applied loads. For this purpose, the test specimens' yield strengths (i.e., 100-100S) were calculated using Equation (1). Then, the specimen's ultimate strength was estimated by multiplying their yield strengths to a shape factor of 1.5. Next, the cross-section area of a bolt was determined using the calculated force as per requirements of AISC (ANSI/AISC360-16, 2016).

The dimensions of the test specimens are given in Table 1. As can be seen, two of the shear plates have a square diaphragm while the diaphragms of the other three specimens have a rectangular shape. The thickness of all shear plates is $1 \mathrm{~mm}$; however, their aspect ratio (height/width) varies from 1.0 to 1.5. As Table 1 shows, the widths and diaphragm heights of the shear plates vary from $60 \mathrm{~mm}$ to $100 \mathrm{~mm}$. It should be mentioned that in literature, different approaches have been suggested for the seismic design of metallic dampers (Lomiento et al., 2010; Manual, 2003; Shen et al., 2017; Tsai et al., 1993). These methods are based on different design concepts and assumptions that can lead to different damper sizes. Moreover, the actual size of a metallic damper is directly related to the considered seismic demand, which can vary based on the intensity of ground motion, type of employed lateral load resisting system, number of stories, number of dampers, etc. Therefore, in this study, the focus was on the aspect ratio of metallic dampers rather than their actual sizes. It is also noteworthy that the size of shear plates in previous studies varies from $100 \mathrm{~mm}$ to $300 \mathrm{~mm}$ (Chan et al., 2009; Sahoo et al., 2015).The yield and ultimate stress of the employed steel plates have been shown in Table 2. As can be seen, the yield stress of the shear plates is $182 \mathrm{MPa}$.

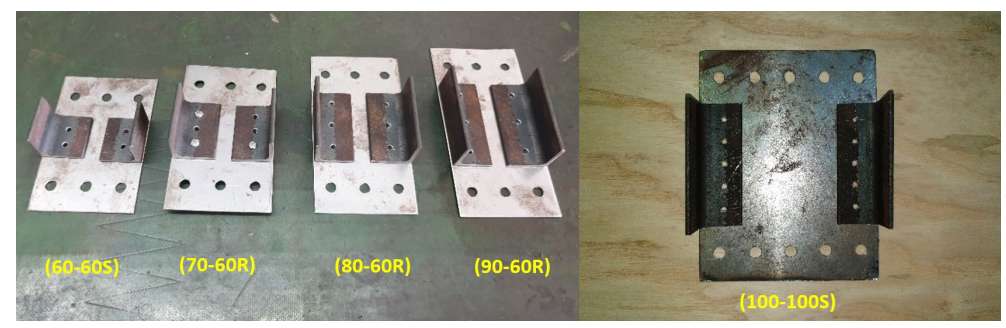

Figure 1 Test specimens.

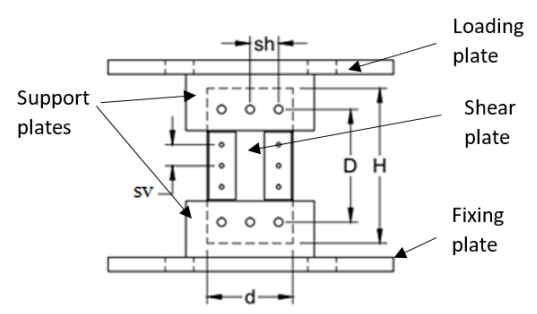

Figure 2 Details of constructed shear plates.

Table 1 Details of constructed shear plates.

\begin{tabular}{|c|c|c|c|c|c|c|}
\hline \multirow{2}{*}{ Specimen } & D & d & H & sv & sh & Aspect ratio \\
\hline & $\mathrm{mm}$ & $\mathrm{mm}$ & $\mathrm{mm}$ & $\mathrm{mm}$ & $\mathrm{mm}$ & $d / D$ \\
\hline $60-60 \mathrm{~S}$ & 60 & 60 & 90 & 10 & 20 & 1 \\
\hline $70-60 R$ & 70 & 60 & 100 & 10 & 20 & 1.17 \\
\hline $80-60 R$ & 80 & 60 & 110 & 15 & 20 & 1.33 \\
\hline $90-60 R$ & 90 & 60 & 120 & 20 & 20 & 1.5 \\
\hline $100-100 \mathrm{~S}$ & 100 & 100 & 130 & 12.5 & 20 & 1 \\
\hline
\end{tabular}

Table 2 Material properties of the test specimens.

\begin{tabular}{ccc}
\hline Element & yield stress (MPa) & ultimate stress (MPa) \\
\hline Shear plates & 182 & 294 \\
Support plates & 328 & 455 \\
Loading plates & 338 & 514 \\
\hline
\end{tabular}




\subsection{Test setup and instrumentation}

As can be seen from Figure 3 the test specimens were fixed on a strong beam from the bottom side of the shear plates and were subjected to a gradually increasing lateral load. A hydraulic jack imposed the lateral load to the loading plate that was connected to the upper side of the shear plates. The out-of-plain movement of the loading plate was restrained by using two L-shaped steel plates. In order to decrease the friction between the loading plate and the L-shape plates, their contact surface was lubricated. The applied loads to the shear plates were measured by using a load cell installed in front of the hydraulic jack. As it is shown in Figure 3, two Linear Variable Differential Transformers (LVDTs) recorded the displacements of the shear plates along the loading direction (i.e., LVDT1 and LVDT2). Another LVDT (i.e., LVDT3) monitored the movements of the shear plate perpendicular to the direction of loading. The applied loads and their corresponding displacements were recorded at each step of loading until shear plates passed their ultimate load. Figure 4 shows the test set up prepared for the specimen 100-100S. It should be mentioned that a monotonic displacement-controlled loading protocol was used for applying the lateral load to the test specimens. At first, all specimens were subjected to $1 \mathrm{~mm}$ displacement, and then the lateral displacement was increased by an increment of $2 \mathrm{~mm}$ until reaching the failure load. It is worth mentioning that, traditionally, quasi-static cyclic loading has been employed by researchers to study the seismic response of structural elements. However, the conducted investigation by Maison and Speicher (Maison and Speicher, 2016) suggests that one-sided cyclic or monotonic tests may be better for describing inelastic seismic demands. Therefore, in this study, a monotonic loading protocol was used.

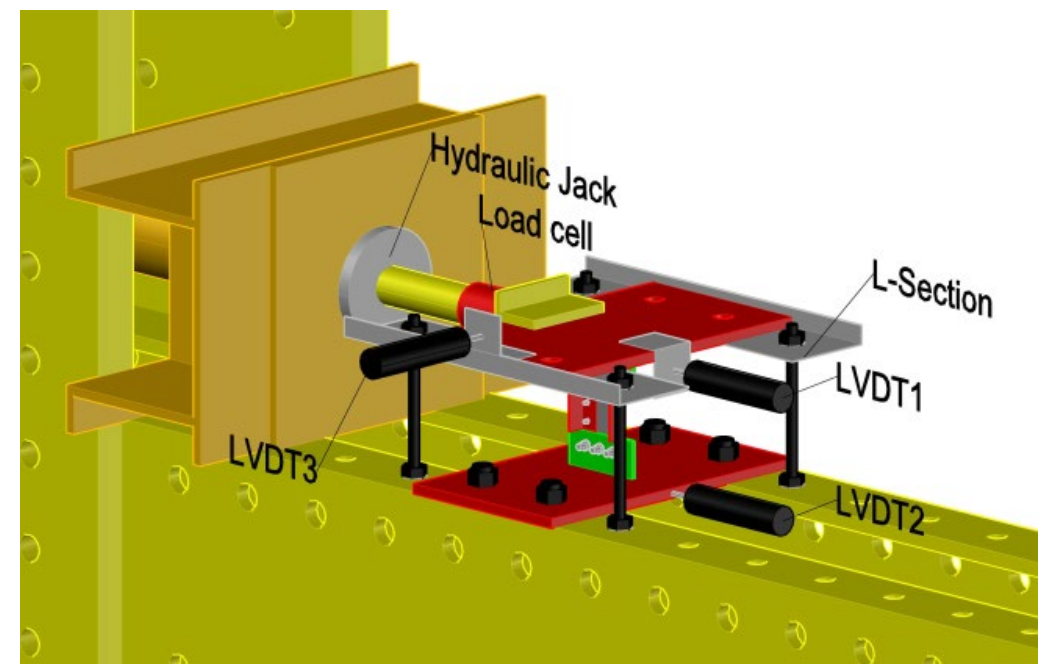

Figure 3 3D view of the test set up.

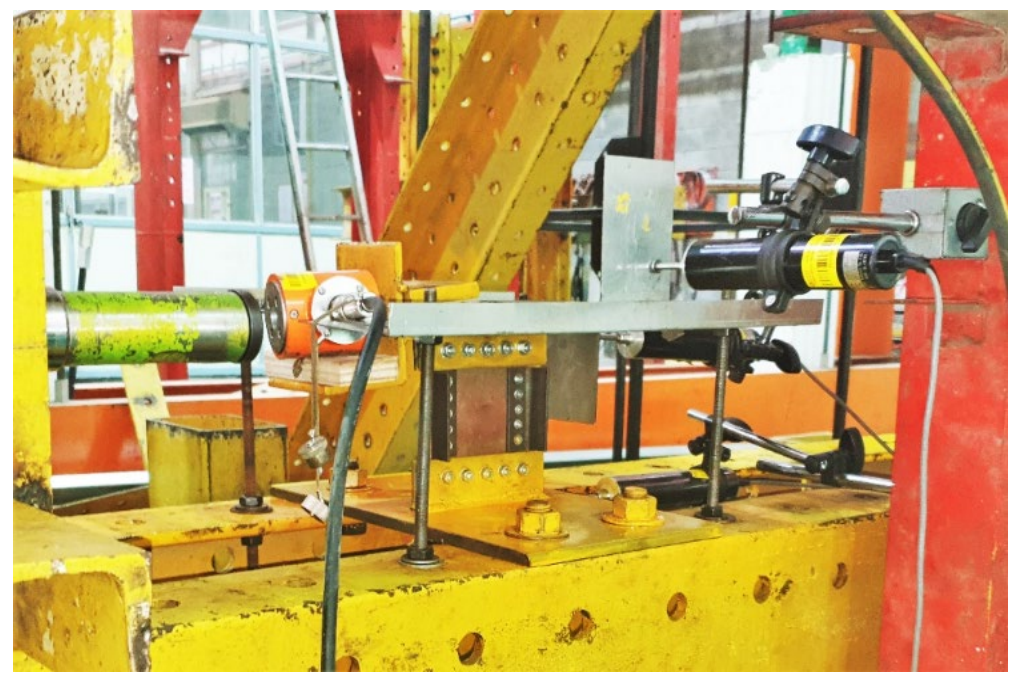

Figure 4 Test set up prepared for the specimen 100-100S. 


\section{RESULTS AND DISCUSSION}

\subsection{Failure modes}

The deformed shapes of shear steel plates at the end of the test have been shown in Figure 5 . As can be seen from this figure, all test specimens have shown a diagonal yield line. The angle of the yield line in shear plates with the square diaphragm was around 45 degrees. However, as the aspect ratio of the shear plates was increased, the angle of their yield line was also increased. No out-of-plane buckling was observed in shear plates. This implied that the steel angles successfully restrained the shear plates from out-of-plane deformation. It should be mentioned that, at the end of the test, because of large deformation in the yield line, the connection between the shear plate of specimen 60-60S (see Figure 5a) and one of the steel angle was failed.

In short, excessive in-plane shear deformation was the main reason for the failure of all test specimens.

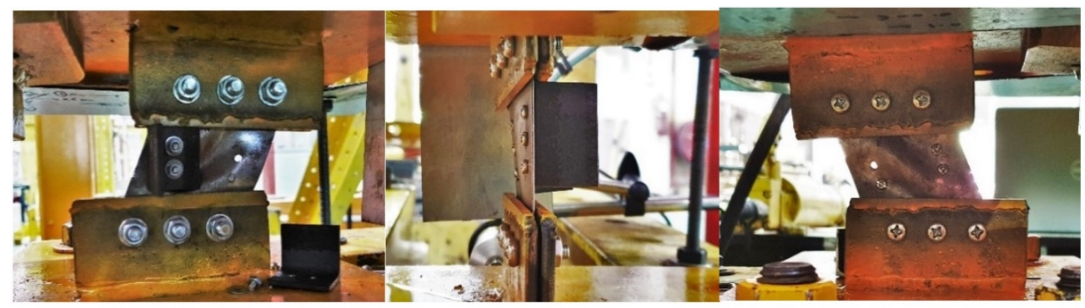

(a)

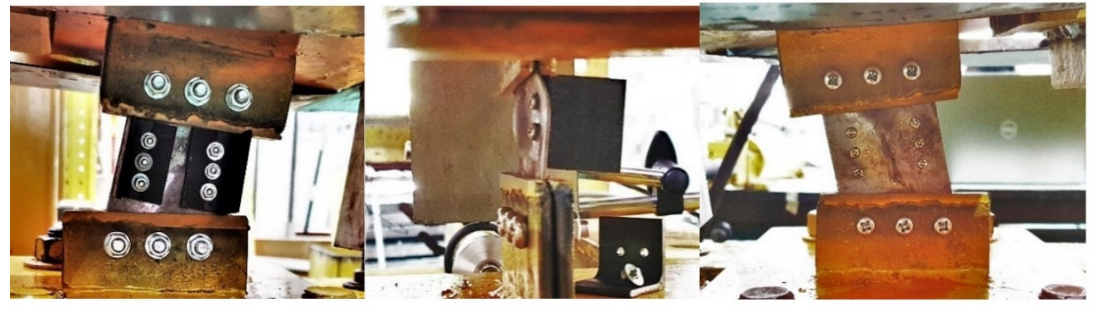

(b)

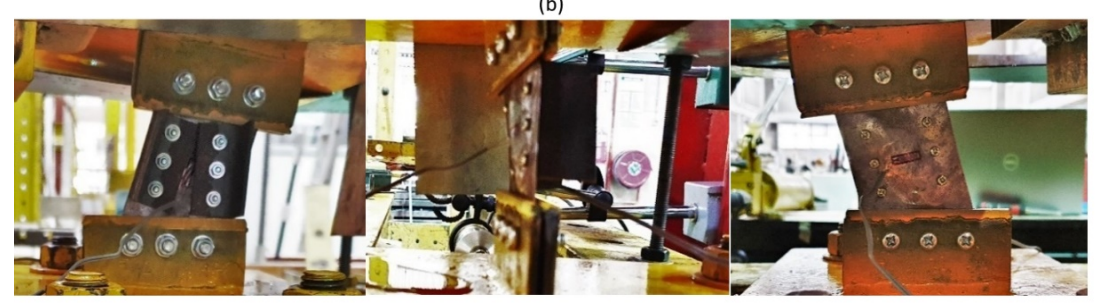

(c)

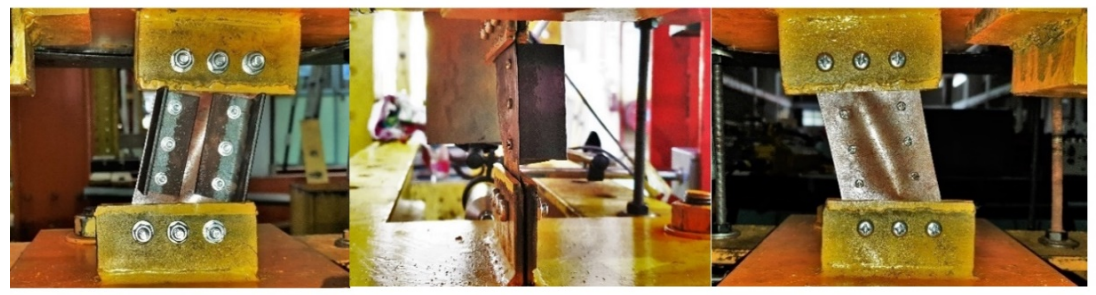

(d)

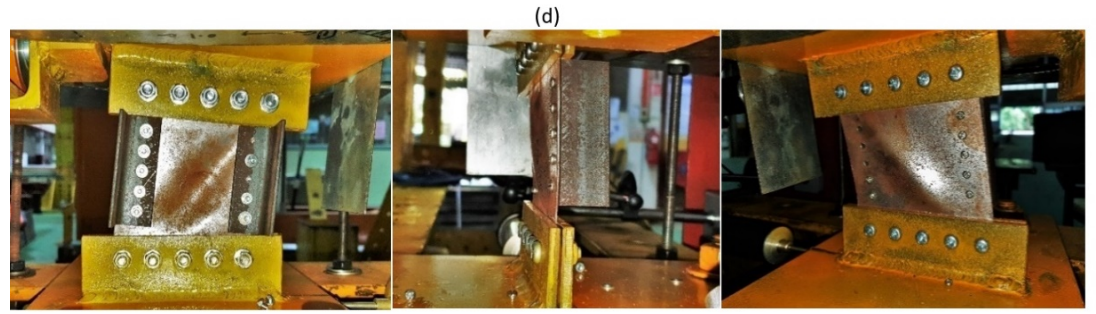

(e)

Figure 5 Failure mode of test specimens (a) 60-60S (b) 70-60R (c) 80-60R (d) 90-60R (e) 100-100S. 


\subsection{Force-displacement relationships}

Figure 6 depicts the obtained force-displacement relationships for all test specimens. It is evident from this figure that the ultimate loads of rectangular shape shear links are very close to each other. This indicates that in the rectangular shear links, the height of steel plates has an insignificant impact on their ultimate load. A comparison between the forcedisplacement relationships of test specimens with the square diaphragm shows that an increase in the size of the shear plate significantly increases the ultimate load. Figure 6 also shows that, in the elastic zone, the square shear plates have a larger secant stiffness when compared with the rectangular shear plates.

As can be seen from Figure 7, the obtained force-displacement relationships were idealized and represented by bilinear curves using the equivalent energy method proposed by FEMA356 (2000). In this method, the area under the bilinear representation should equal to the area under the force-displacement curve. Therefore, an iterative graphical procedure is needed to locate the two line segments of the bilinear representation. Besides, in the bilinear representation, the first line should intersect with the force-displacement curve at $60 \%$ of the effective yield strength (i.e., $F_{y}$ ). The slope of the bilinear curve before the effective yield strength (i.e., Fy) shows the effective stiffness of the shear plates, and after that, indicates their post-yield stiffness. The displacement ductility ratio (i.e., $\mu$ ) of shear plates can be calculated as the ratio of displacement at the effective yield strength (i.e., $\Delta y$ ) to the displacement at the ultimate load (i.e., $\Delta \mathrm{u}$ ). Figure 8 shows the bilinear representation of force-displacement relationships, and Table 3 summarizes the obtained results from such idealization.

As can be seen from Table 3, an increase in the aspect ratio of rectangular diaphragms decreases their initial and effective stiffness. It should be mentioned that the initial stiffness of dampers was calculated based on the measured force corresponding to a displacement of $3 \mathrm{~mm}$. On the other hand, an increase in the size of square diaphragms increases the initial and effective stiffness of shear plates. The obtained results also show that the square diaphragms have a larger effective and post-yield stiffness when compared with the rectangular diaphragms. This implies that, after the yield point, the square diaper gams have a larger reserved strength. It is also noteworthy that, in addition to the initial stiffness, the effective and post-yield stiffness of square diaphragms increases as their size increases.

It can also be seen that similar to the ultimate load, the effective yield strength of the rectangular diaphragms does not change significantly as the aspect ratio increases. However, in square diaphragms, a significant increase can be seen as the size of the shear plate increases. Table 3 also shows that the displacement ductility ratios of square diaphragms are larger than that of rectangular diaphragms. The obtained results also show that an increase in the aspect ratio of rectangular diaphragms or an increase in the size of shear plates decreases the displacement ductility ratio.

The obtained results from the experiment imply that because of developing a 45-degree tension field, the square diaphragms have superior performance when compared with the rectangular diaphragms. In other words, since the shear plastic yielding of the metallic plate is the primary source of energy dissipation, dampers that can provide a larger tension field can dissipate more energy and consequently can have a larger ductility ratio. Therefore, square plates are preferable for use in the metallic dampers that take advantage of yielding shear plates because, unlike the rectangular plates, they develop a 45-degree tension field. It should also be mentioned that this observation correlates well with the findings of other researchers (Chan et al., 2009).

The area under the force-displacement curves was calculated and represented as the cumulative energy dissipation in Figure 9. It is evident from this figure that compared with rectangular diaphragms the square diaphragms have larger energy dissipation capacity. Besides, an increase in the size of square diaphragms has increased their energy dissipation capacity. It is also noteworthy that an increase in rectangular diaphragms' height has decreased their energy dissipation capacity. These observations correlate well with the obtained results for the dampers' ductility ratio. As mentioned earlier, square diaphragms' larger energy dissipation capacity is related to the developed 45-degree tension fields.

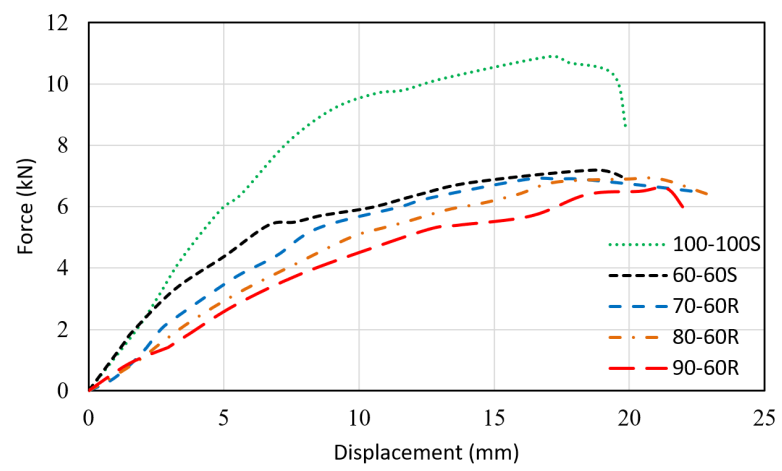

Figure 6 Force-displacement relationships. 


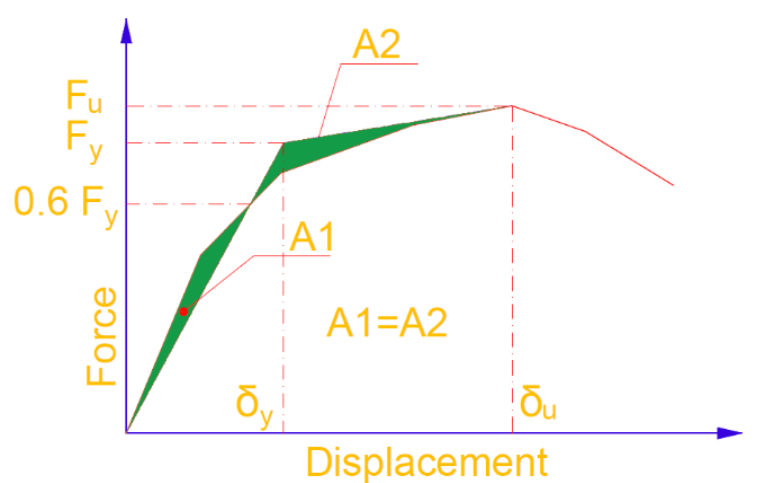

Figure 7 Bilinear representation of force-displacement relationships.

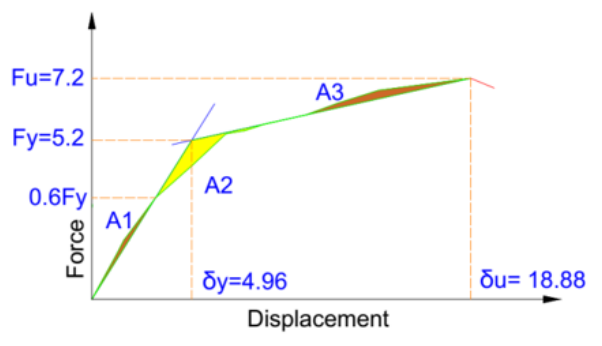

$60-605$

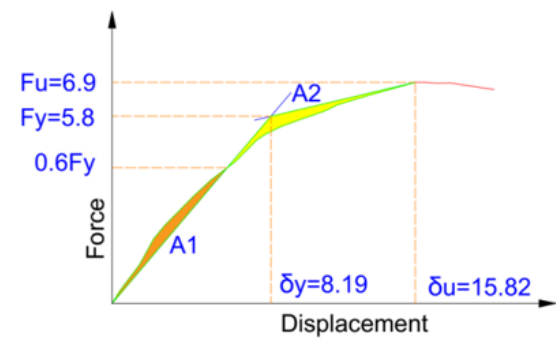

(b)70-60R

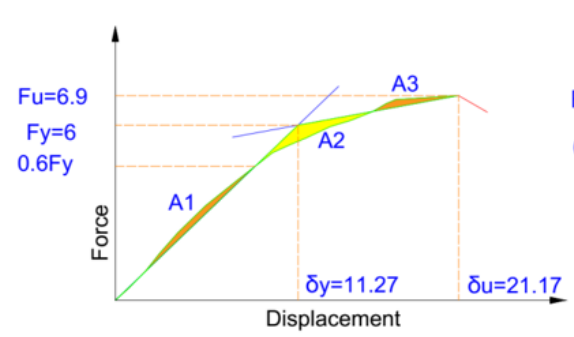

(c) $80-60 \mathrm{R}$

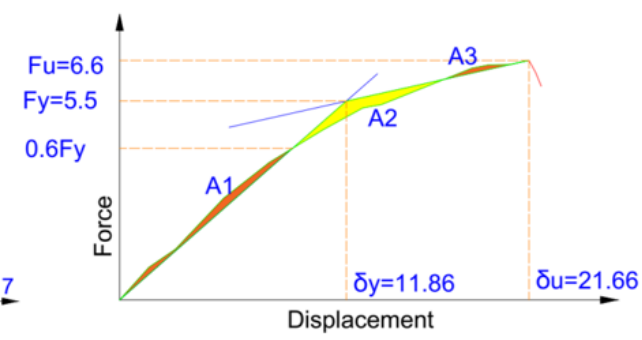

(d) $90-60 R$

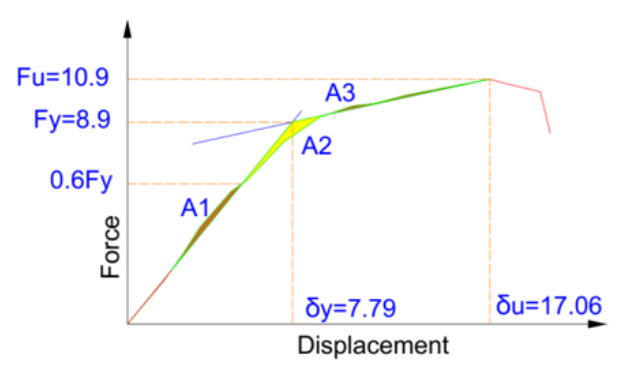

(e) $100-100 \mathrm{~S}$

Figure 8 Bilinear representation of backbone curves.

Table 3 Summary of the obtained results from bilinear representation of backbone curves.

\begin{tabular}{|c|c|c|c|c|c|c|c|c|}
\hline \multirow{2}{*}{ Specimen } & \multirow{2}{*}{$\begin{array}{c}\text { Initial } \\
\text { stiffness } \\
\text { (kN/mm) }\end{array}$} & \multirow{2}{*}{$\begin{array}{l}\text { Effective stiffness } \\
\text { (kN/mm) }\end{array}$} & \multirow{2}{*}{$\begin{array}{l}\text { Post-yield } \\
\text { stiffness } \\
\text { (kN/mm) }\end{array}$} & \multicolumn{2}{|c|}{ Displacement $(\mathrm{mm})$} & \multicolumn{2}{|c|}{ Strength (kN) } & \multirow{2}{*}{$\begin{array}{c}\text { Dis. ductility ratio } \\
(\delta \mathrm{u} / \delta \mathrm{y})\end{array}$} \\
\hline & & & & $\delta u$ & $\delta y$ & $\mathrm{Fu}$ & Fy & \\
\hline $60-60 \mathrm{~S}$ & 1.2 & 1.05 & 0.14 & 18.88 & 4.96 & 7.2 & 5.2 & 3.81 \\
\hline $70-60 R$ & 0.75 & 0.71 & 0.14 & 15.82 & 8.19 & 6.9 & 5.8 & 1.93 \\
\hline $80-60 R$ & 0.6 & 0.53 & 0.09 & 21.17 & 11.27 & 6.9 & 6 & 1.88 \\
\hline $90-60 R$ & 0.5 & 0.46 & 0.11 & 21.66 & 11.86 & 6.6 & 5.5 & 1.83 \\
\hline $100-100 S$ & 1.30 & 1.14 & 0.22 & 17.06 & 7.79 & 10.9 & 8.9 & 2.19 \\
\hline
\end{tabular}




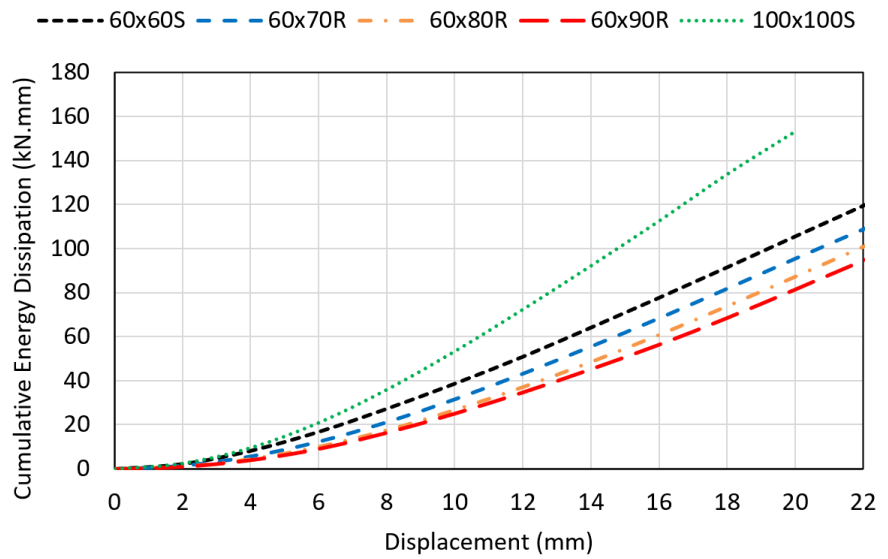

Figure 9 Energy dissipation of tested dampers.

\subsection{Comparison with analytical calculations}

If the elastic shear buckling is avoided, the shear yield strength (Sy) of a square steel plate can be calculated by Eq. (1) (Chan et al., 2009). In order to avoid the elastic shear buckling, the slenderness ratio of the steel plate (i.e., $d / t)$ should be smaller than the value calculated by Equation (2). In these equations, $d$ is the width of the steel plate, and $\sigma y$ is its yield stress. Moreover, $\mathrm{t}$ is the thickness of the steel plate. Table 4 summarizes the obtained shear yield strengths for the tested specimens using Equation (1). It should be noted that the slenderness ratio of all shear plates is below the limit given by Equation (2) (i.e., 128). As can be seen from Table 4, the yield strength of the specimens with the square diaphragm has been slightly overestimated by Equation (1). The estimated yield strengths of 60-60S and 100-100S specimens are, respectively, $21 \%$ and $18 \%$ larger than the values obtained from the experiment. The difference in the shear yield strengths can be attributed to the bolt slippage and geometrical imperfection and deformation of steel angles, as have been reported by other researchers (Chan et al., 2009).

$$
\begin{aligned}
& S_{y}=\left(\sigma_{y} / \sqrt{3}\right) t d \\
& \frac{d}{t}=\frac{1732}{\sqrt{\sigma_{y}}}
\end{aligned}
$$

Table 4 Comparison between yield strengths.

\begin{tabular}{ccccc}
\hline \multirow{2}{*}{ Specimen } & Shear yield strength $(\mathbf{k N})$ & & Effective yield strength $(\mathbf{k N})$ & \multicolumn{2}{c}{ Slenderness ratio } \\
\cline { 2 - 3 } & Eq. (1) & experiment & D/t \\
\hline 60-60S & 6.30 & 5.2 & 60 \\
100-100S & 10.51 & 8.9 & 100 \\
\hline
\end{tabular}

\section{CONCLUSION}

This study investigated the effects of shear plates' aspect ratio on their mechanical behavior. Five shear plates were constructed and subjected to a gradually increasing lateral load. The thickness of all shear plates was $1 \mathrm{~mm}$; however, their aspect ratio varied from 1.0 to 1.5. The obtained results indicated that an increase in the aspect ratio of shear plates decreased their initial stiffness, effective stiffness, and displacement ductility ratio. However, the difference in the ultimate load of shear plates with different aspect ratios was insignificant. Besides, the test specimens with square diaphragm had a larger displacement ductility ratio, initial and effective stiffness when compared with the specimens having a rectangular diaphragm. An increase in the size of specimens with the square diaphragm increased the post-yield and effective stiffness but decreased the displacement ductility ratio. It was also found that the analytically calculated shear yield strengths were up to $21 \%$ larger than the values obtained from the experimental works. It was concluded that shear plates with the aspect ratio of one had a better mechanical behavior for being used as the shear link in metallic dampers. It should be mentioned that an ideal metallic damper should have a large energy dissipation capacity and ductility ratio and provide sufficient elastic stiffness to resist in-service lateral loads like wind loads. The obtained results 
from this study are valid only for plates with a thickness of $1 \mathrm{~mm}$. More investigations should be carried out to generalize this study's findings for plates with different thicknesses.

\section{Acknowledgments}

The authors would like to thank the Ministry of Higher Education of Malaysia and Universiti Teknologi Malaysia for their financial support through the research grant vote numbers of 5F365, $16 \mathrm{~J} 24$.

Author Contributions: Conceptualization, AS Aljawadi, M Vafaei, and SC Alih; Methodology, M Vafaei and SC Alih; Experimental Works, AS Aljawadi and M Vafaei; Writing - original draft, AS Aljavadi; Writing - review \& editing, M Vafaei and SC Alih; Funding acquisition, SC Alih; Resources, AS Aljavadi and SC Alih; Supervision, M Vafaei and SC Alih.

Editor: Marcílio Alves

\section{References}

ANSI/AISC360-16. (2016). Specification for structural steel buildings. 130 East Randolph Street, Suite 2000, Chicago, Illinois 60601: American Institute of Steel Construction.

Bergman, D. M., and Goel, S. C. (1987). Evaluation of cyclic testing of steel-plate devices for added damping and stiffness: Department of Civil Engineering, University of Michigan.

Black, C. J., Makris, N., and Aiken, I. D. (2004). Component testing, seismic evaluation and characterization of bucklingrestrained braces. Journal of Structural Engineering, 130(6), 880-894.

Chan, R. W. K., and Albermani, F. (2008). Experimental study of steel slit damper for passive energy dissipation. Engineering Structures, 30(4), 1058-1066.

Chan, R. W. K., Albermani, F., and Kitipornchai, S. (2013). Experimental study of perforated yielding shear panel device for passive energy dissipation. Journal of Constructional Steel Research, 91, 14-25.

Chan, R. W. K., Albermani, F., and Williams, M. S. (2009). Evaluation of yielding shear panel device for passive energy dissipation. Journal of Constructional Steel Research, 65(2), 260-268.

Chen, Z., Ge, H., and Usami, T. (2006). Hysteretic model of stiffened shear panel dampers. Journal of structural engineering, 132(3), 478-483.

Deng, K., Pan, P., Li, W., and Xue, Y. (2015). Development of a buckling restrained shear panel damper. Journal of Constructional Steel Research, 106, 311-321.

Deng, K., Pan, P., Sun, J., Liu, J., and Xue, Y. (2014). Shape optimization design of steel shear panel dampers. Journal of Constructional Steel Research, 99, 187-193.

Edrees, T. (2015). Structural control and identification of civil engineering structures. Luleå tekniska universitet.

FEMA356. (2000). Prestandard and Commentary for the Seismic Rehabilitation of Buildings, American Society of Civil Engineers (ASCE). Reston, Virginia, USA.

Karavasilis, T. L., Kamaris, G. S., and Tzimas, A. S. (2014). Buildings and Bridges Equipped with Passive Dampers Under Seismic Actions: Modeling and Analysis. Encyclopedia of Earthquake Engineering, 1-15.

Lee, C.-H., Ju, Y. K., Min, J.-K., Lho, S.-H., and Kim, S.-D. (2015). Non-uniform steel strip dampers subjected to cyclic loadings. Engineering Structures, 99, 192-204.

Liu, Y., Aoki, T., and Shimoda, M. (2013). Strain distribution measurement of a shear panel damper developed for bridge structure. Journal of Structures, 2013.

Liu, Y., and Shimoda, M. (2013). Shape optimization of shear panel damper for improving the deformation ability under cyclic loading. Structural and Multidisciplinary Optimization, 48(2), 427-435. 
Lomiento, G., Bonessio, N., and Braga, F. (2010). Design criteria for added dampers and supporting braces. Seismic Isolation and Protection Systems, 1(1), 55-73.

Maison, B. F., and Speicher, M. S. (2016). Loading protocols for ASCE 41 backbone curves. Earthquake Spectra, 32(4), 25132532.

Manual, J. (2003). Design and construction manual for passively controlled buildings. Japan Society of Seismic Isolation (JSSI), Japan.

Nakashima, M., Iwai, S., Iwata, M., Takeuchi, T., Konomi, S., Akazawa, T., et al. (1994). Energy dissipation behaviour of shear panels made of low yield steel. Earthquake engineering \& structural dynamics, 23(12), 1299-1313.

Nath, M. (2016). Seismic design and performance of Yielding Shear Panel Device. Concordia University.

Ohsaki, M., and Nakajima, T. (2012). Optimization of link member of eccentrically braced frames for maximum energy dissipation. Journal of Constructional Steel Research, 75, 38-44.

Sahoo, D. R., Singhal, T., Taraithia, S. S., and Saini, A. (2015). Cyclic behavior of shear-and-flexural yielding metallic dampers. Journal of Constructional Steel Research, 114, 247-257.

Shen, H., Zhang, R., Weng, D., Gao, C., Luo, H., and Pan, C. (2017). Simple design method of structure with metallic yielding dampers based on elastic-plastic response reduction curve. Engineering Structures, 150, 98-114.

Tsai, K.-C., Chen, H.-W., Hong, C.-P., and Su, Y.-F. (1993). Design of steel triangular plate energy absorbers for seismic-resistant construction. Earthquake spectra, 9(3), 505-528.

Vafaei, M., Omar Sheikh, A. M., and C. Alih, S. (2019). Experimental study on the efficiency of tapered strip dampers for the seismic retrofitting of damaged non-ductile RC frames. Engineering Structures, 199.

Yang, T. Y., Banjuradja, W., and Tobber, L. (2018). Experimental Test of Welded Wide Flange Fuses. Key Engineering Materials, $763,414-422$.

Zhang, C., Zhang, Z., and Zhang, Q. (2012). Static and dynamic cyclic performance of a low-yield-strength steel shear panel damper. Journal of Constructional Steel Research, 79, 195-203. 